\title{
Prerequisites Change Production and Business Activities
}

\author{
Alexander Emelyanovich Miller \\ Omsk State University n.a. F.M. Dostoevsky, Russia, 644077, Omsk, Mira Street., 55A; \\ Marina Victorovna Lysenko \\ Tyumen State Oil and Gas University, Russia, 625000, Tyumen, Volodarsky Street., 38; \\ Olga Sergeevna Makarova \\ Tyumen State Oil and Gas University, Russia, 625000, Tyumen, Volodarsky Street., 38
}

Doi:10.5901/mjss.2015.v6n4p395

\begin{abstract}
In the article the goal of the theoretical foundations and methodology development of industrial activity changes of business structures. Proved the practical importance of the classical process-system approach to identify prerequisites change production and business activities and opportunities to anticipate changing technologies, customers, competitors, organizational and economic factors affecting the internal changes that occur as a result of forced adaptation to changes in the business structure of the environment. The features of the formation of the prerequisites change production and business activities. Grounded organizational, economic and social conditions change production and business activities. Reasoned system of evaluation criteria and indicators for planning changes production and business activities. Proposed and argued the key areas for further research problematic changes in production activity of enterprise structures.
\end{abstract}

Keywords: production and business activities, business structure and criteria changes, profit.

\section{Introduction}

In modern conditions for entrepreneurial structure affects a huge number of different factors, content and direction. For business structure, carrying out production activities, defining its function and purpose in the economy of the state, is the production process. In this regard, the greatest interests are those socio-economic factors, the impact of which could cause a major production elements and connections between them. Guided by this logic, it is necessary to identify the key assumptions, the baseline scenario of changes in production and business activities.

A system of organization of production can be identified organizational, economic and social conditions change production and business activities.

Organizational prerequisites can be grouped into two main blocks of changes:

1. Changes associated with the need to improve the functioning and interaction of elements of the production process: the organization of work of participants of the production process; organizing the use of tools; organization of the movement of objects of labor in production; information flow in manufacture.

2. Changes associated with the need to improve the production structure of the business structure and its structural subdivisions: organization of production processes for the production of primary products; organization of complex preparation of production and development of new products; organization of production planning and product quality; organization of production infrastructure business structure.

The bases of the economic prerequisites change production and business activities constitute the processes associated with the organization of intra-economic relations; organization of logistics processes, production, marketing and sales.

The social premises should include changes in the organization and management personnel; organization of social processes at work.

Each of these groups to solve certain problems, the content of which is the basis for determining the appropriate changes in the production and business activities. 


\section{Methodology}

\subsection{Methodological basis for the organization of the production process}

The production process, as the basis of functioning of production and business structure, is also a source of major changes in production and business activities. Insufficient efforts to organize labor members of the production process leads to a complex socio-economic consequences - lack of qualified staff, the implications of which substantially impairs the functioning of the enterprise structure. Often, changes in production processes associated with the personnel changes, a set of new and old employees with dismissal enterprise structure. It is important to consider the consequences associated with changes in personnel involved in the production process. After the success of the enterprise structure often heavily dependent on primary production personnel, especially if he is irreplaceable. After changes in the personnel directly affect the production of business structure and, consequently, affect all other spheres of activity (Aven, 1991). The same, for example, can be said about the highly specialized employees. Losing them business structure loses some of its ability to conduct work requiring specialization.

Abnormalities in the organization of the use of tools from the point of view of the functioning of business structure lead to premature wear of the elements of fixed capital, and the loss of their unmet because of this productive capacity. This situation is equally characteristic of all production and business structures, although, of course, each industry has specific features. Data such as the dynamics of fixed assets, depreciation of fixed assets, the rate of renewal of fixed assets, retirement rate of fixed assets give an idea of the need to improve the analytical work. Of course, the analytical assessment must be detailed on separate elements of fixed assets (buildings, equipment), in their life, of their growth, types of production and manufacturing and structural subdivisions of business structure, etc.

Cause changes in the organization of the movement of objects of labor in production may be low interest personnel to improve the smooth movement of objects of labor, due to the use of weak incentives for workers (Barnett and Carroll, 1995). A similar situation can be and with the organization of information flows in production, when the task of designing the information model of enterprise structure and its subsidiaries are not dealt with in full; the formation of information flows is not conducive to the development of production; selection of the information needed for a certain level of control and related subsystems is not moving fast enough and on time; transmission of information to all units of business structure is carried out very late.

\subsection{Elements of the production process}

Production and structure of the expressed elements defines the interaction of the manufacturing process and mix the partial processes in the space (Bogdanov, 1989). System of formation of industrial structure solves the problem of determining the composition of the units in the business structure; selection and justification of the nature of their specialization and the establishment of industrial relations between them; optimization of production and others. The reasons for the low efficiency of the production structure are conserved its structure and inertia due to the lack of flexible response to changes in the external environment.

Wrong choice of forms and methods of organization of production processes usually leads to high production costs, which in itself is a major prerequisite for reducing the stable functioning of the business structure. Do not use technical innovations that allow reducing production costs, can lead to incorrect pricing on the market. If the business structure not constantly working to reduce production costs, then there is always the threat of losing competitiveness in the market.

As part of an integrated, pre-production and development of new products is very important can be a threat to the backlog of engineering and technology, applied business structure. This threat, if not avoided, depriving entrepreneurial structure of competitiveness in the market and the possibility to function normally.

Reduced effectiveness of the organization to ensure product quality reflected in reduced quality after-market launch, and as a result, decreases the reputation of the business structure in the eyes of consumers.

Planning solves the problem of a rational combination of production processes in time. It is more susceptible to disruptions in their own production plans or innovative projects. The reasons for this situation may be a lack of emergency funds, failure to comply with the technology transfer of qualified personnel in other business organizations.

Significant failures in the organization of production infrastructure subsystem provoke crises. All this points to the real manifestation of the threat of accidents and emergencies in the business structure. For a significant number of business structures are much more relevant is the task of reducing the likelihood of contingencies and emergencies due to unintentional actions of staff, which can only be solved as a result of normal trouble-free operation of enterprise 
structure. Thus laid a solid foundation for the achievement of economic success in production.

Intra economic relations provide for the implementation tasks of economic isolation units that make up the production and business structures; the introduction of various forms of intra-cost accounting; the creation of institutional conditions for effective work in a variety of forms of ownership (Kleyner, 2008). Do not perform the tasks is the reason that causes the need to change intra-relations, which are often exacerbated by the financial interests of the business units of the structure and top managers.

Organization of logistics production shortfalls daily exposed to the threat of raw materials due to the failure of signed contracts for the supply. The causes of this situation may be different, for example, unexpected situation from suppliers; technically impossible to produce the necessary business structure products; decision supplier of breaking the contract and changing consumer; decision supplier to change the terms of the contract - terms, prices, volumes, quality requirements for supplied products and others.

A serious threat to production activities in low-functioning marketing and sale of a loss of its market niche product, ie impossibility of marketing their goods with the necessary to ensure the normal reproductive process profit (Van de Ven and Poole, 1995). The causes of this critical situation, the business structure may be a variety of factors, both external and internal.

\section{Results}

Dynamics of production and demand is cyclical. Therefore, periodically come times of general decline in production. The result is a decrease, sometimes quite sizeable, demand for products business structure and prices for it. This leads to a decline in production in the business structure and the inability to sell products at a price that compensates for the cost of production and provide the necessary income (Miller, 2013).

Another major reason for the loss of business structure niche market may be significant technical and technological shifts that cause changes in demand for certain types of goods.

Another factor that can cause a loss of business structure niche markets - the aggressive policies of competitors. This factor is permanent. We have a lot of leverage competitors displacement competing business structure of the market: active advertising, improving the quality and range of products, the correct organization of sales and trade, better service, lower production costs and prices, etc.

And finally, the reason for the loss of market position of each production and business structure may be a change in the political and economic situation. On the foreign market it apart from the already mentioned above changes in demand due to changes in economic growth may be discriminatory measures of some states in relation to the Russian goods (Adizes, 2011).

Failure to fulfill the tasks of the organization and personnel management leads to inadequate assessment of managers of the importance of innovation activities of the business structure and the necessary qualifications leading experts.

Lack of good governance of social processes in the production causes one of the most serious problems in the production activity of enterprise structure - opportunism staff. In this case, under the opportunistic behavior of staff should understand the hidden violation of the employees and managers of the business structure of their obligations to it. Opportunism staff manifested, for example, neglect of duties, breach of contract, the transfer of information to a third party, etc.

It should be noted that the sustainability of production and business structure is associated with the formation of mechanisms aimed at creating the conditions to maximize resources in the production process.

By providing entrepreneurial structure of production activities should focus on preventive measures aimed at establishing a sustainable operation of the production process, that is, the leveling of negative factors external and internal environment. This system, in fact, is some significant obstacle to the emergence of negative trends in the production activity of enterprise structures (Williamson, 1979). Sophisticated and systematically organized system of stable functioning of enterprise structure enables management to effectively influence the entire production process. To avoid inefficient use of resources, ensuring production activities, it is important to identify a number of locations to determine the rhythm, form and event-box are in relation to each other reflexive systems.

Firstly, this guide business structure: managers and owners.

Secondly, it is the staff of enterprise structure, which is located in a very ambiguous situation. On the one hand, the staff is interested in the prosperity of its business structure, as is rewarded for their labor - wages. On the other hand, it is employees of enterprise structure, contrasting the position of business administration structure.

Third, it's counterparties under which it should be understood business organizations interested in obtaining access 
to resources.

\section{Discussion}

\subsection{Situations specific to business structures}

Studies have shown that in terms of production activities, there are two situations that are typical for most business organizations.

The first situation - highly profitable business structure, effectively functioning. Typically, these business organizations position of the administration and staffs are the same due to the coincidence of interests (increasing the profitability of business structure - an increase in the yield of each of the participants in the production process) and obtain timely reinforcement installations. In such circumstances, the interest of staff in sustainability and stability of enterprise structure is obvious, and the administration activity is reduced to the construction of depth control system of preventive measures aimed at reducing the likelihood of crises on productive activities (Klein and Leffler, 1981).

The second situation - untenable business structure in distress. Such business structures are slowly but surely slipping into bankruptcy. Administration limited resources to create a sustainable operation, and is often preoccupied only with their own individual interests, unable to bring the situation under control. In conditions of chronic non-payment of wages staff demoralized business structure and cannot speak for the support program for the development of production, developed by the administration. Contractors are, in contrast, are stepping up their activities in relation to such business structures. Often these business structures can be observed or "failover" or output resources of enterprise structure. One way or another, but in most cases the process ends readjustment business structure, sale of its assets. Lack of available resources allows us to conclude that the traditional tools and techniques to create a sustainable operation and methods of influence on the staff of business structure is effectively used in cost-effective business structures may not be as optimal under these conditions (Huber and Glick, 1993).

Possible directions for an effective system of sustainable production activities from insolvent enterprise structure can be considered from the standpoint of strategic behavior and from the standpoint of operational activities. Both aspects are equally important, interrelated, but the original aspect of the strategic approach. Prompt action should specify the structure and business strategy serve as a means for its implementation. In terms of the distribution of efforts and resources of business structure between the strategic and operational activities should primarily take into account the complexity and variability of the environment and thus the characteristic of negative factors. For example, if a business structure is working with regular customers, whose number is optimal, and the calculation is carried out with clients on a full prepayment and business structure is provided with orders, it is likely that the threat of financial and economic structure of the business of the clients will be small. Therefore, the production of special rules of conduct of business structure to customers in the form of a strategy for sustainable operation of industrial activity may be directed at least money and effort. Conversely, if the business structure constant dependence on products shipped from insolvent customers, the need for strategic decision-making in relation to such customers is extremely important, and prompt action will be completely subordinated to an effective strategy.

The most important result of the operation of production and business structure is the choice of development strategy and develop operational measures for its implementation (Chambeau and Mackenzie, 1986).

It should be primarily based on an assessment of the medium and the required completeness of strategic decisions. With the full content of the strategy should comply with the basic principles of strategic approach: focus on compliance with the strategy and management of the environment of the environment, the absence of a fully similar situations and individual strategic decisions are consistent with other strategic decisions and, above all, with the overall economic strategy, creating the conditions for successful implementation of the strategy and development capabilities of enterprise structure (Shermet, 2010).

Thus, in the present conditions identify prerequisites possible failures in the production activity of enterprise structure allows to minimize the impact of crisis situations, to neutralize the impact of negative factors on the sustainable operation of the entire system of production and ensure the integration of all groups of processes in a single production process.

\subsection{Intercompany relationships and planning changes}

As a basis for planning changes to production activity of enterprise structure should be considered intercompany relationships, since we are talking about the reflection in the structure of industrial relations. 
As regards the economic basis of intra-relations, as such, are the specific forms of existence of industrial relations, consciously, purposefully used as a tool of industrial activity. This is nothing like the outside "surface" layer of industrial relations, the form of their expression in practice. Thus, at the level of business structure appears directly price (not cost), profit (rather than the surplus product), business planning (rather than the law of planned development), wages (rather than the law of distribution according to work)

Globalization of the economy and a predetermined feature improving production activities, as focus on achieving the highest quality results. Therefore, one of the key reasons for the restructuring of forms and methods of planning a transition to a fundamentally new qualitative indicators work. This transition is not completely random; it is due to qualitative changes in the economy at this stage of development.

This disparity is caused mainly by the fact that, on the one hand, the trend towards quantitative measure of its performance, on the other hand, underestimation of the role and importance of high-quality gauges performance. Of course, during the formation and development of the productive capacity of the quantitative approach was justified. When, finally, there has been some level of stable formation, the existing "evaluation criteria" have become an important limiting factor of production. A new stage of economic development and demanded new methods of quality planning, rationalize restructuring operation of the entire management mechanism, putting it in direct dependence on achieving quality results (Chandler, 1990).

In the practice of management there are negative developments, such as the low rate of production growth, weak growth of its efficiency, low quality of products. Existing targets were not allowed to objectively evaluate the work of a team.

There is a need of an integrated approach to planning changes of industrial activity. It is up to the rational organization of all parts of the mechanism of management depends on improving the effectiveness of production activity. If you cannot solve the problems of planning, the problem of improving the organizational management structure, we cannot count on the fact that the production will perform all the functions that are assigned to it.

Thus, considering the production and business activities in terms of its relationship with the system of categories and laws of economic theory, we can conclude that it is the basis of the relations of production. But to determine the content and structure of the activity that is not enough (Encyclopedia ... 2010). In the current economic conditions the main way of improving and developing production and business activities is to enhance its effectiveness.

Further research planning changes of industrial activity involves not only the optimization of targets, but also the improvement of the planning methodology, as defined management process, planning procedures.

The need to identify changes in production activity involves a comprehensive description of it. To do this, use a system of quality evaluation criteria and their respective quantitative change planning of industrial activity from the standpoint of compliance with the basic principles of organization of economic relations and production requirements.

The main economic criteria change production activities are: the efficiency of the enterprise structure as a whole; the contribution of each structural unit in the performance of the enterprise structure.

The first of these qualitative criteria to obtain quantitative characteristics with known performance indicators of business structure.

Along with the overall assessment of business structure is necessary to analyze the contribution of each structural unit in the economy of enterprise structure, which can be quantitatively measured using another main indicator profitability.

The high level of profitability is provided by increasing the volume of output in the secured demand; decrease production costs and reduce the volume and size of sanctions. These indicators have an impact on the effectiveness of capital across product profitability and allow quantifying the positive or negative contribution of each structural unit in the economy of enterprise structure (Casson, 1982).

The increase in output (works and services) in the amount of the security or the reduction in demand due to the fault of the individual structural units leads to an increase or decrease in the production and sales of products business structure and, consequently, an increase or decrease of its profit. The same result is obtained and change in production costs. Negative factors affecting the profit margin are also economic damage and material losses sanctions.

All of these factors affect the ultimate profit enterprise structure should be taken into account in determining the profitability of production at the level of each structural unit.

This approach allows us to establish the reasons for changing the actual profit of the structural unit related to the change compared with the estimates of production costs, as well as the economic damage of the sanctions.

Overrun the actual cost of production compared with the normative should be covered by the profit of the structural unit, therefore, the actual profit is reduced compared with the standard value overruns on production costs (Soase, 1937). Accordingly, the economy added costs leads to an increase in profits. 


\subsection{Parameters estimation of efficiency changes of industrial activity}

Given the complexity of the transitional phase of a competitive economy and instability of the economic situation in the country, it should be noted that the main indicators to measure the performance of structural units may not always serve as a basis for planning changes to production activities (Brockhaus, 1982). Therefore, along with qualitative and quantitative assessment of changes at the level of efficiency of structural units in the business structure of the main criteria and indicators, an evaluation by a particular criteria and corresponding additional indicators those meets the basic principles of performance management.

Evaluating the effectiveness of changes in industrial activity from the perspective of its compliance with one of the basic principles - providing a relative property, organizational and economic independence of the structural units - is carried out through a series of partial criteria.

The degree of structural units of property independence depends on whether they are owned and leased production assets. This criterion gets quantitative characteristic depending on the proportion of leased fixed production assets in the total amount of productive assets structural unit.

The degree of economic independence can be quantitatively measured as a function of the degree of involvement of the structural units in the contractual and financial relations. Additional quantitative characterization of this criterion is ensured by such factors as the account of the special primary and secondary production, the degree of involvement in the system of economic relations departments and services of the administrative apparatus.

The main principles of the organization of intra-economic relations are also yields structural units of business structures, economic interests and economic responsibility of labor collectives of structural units.

Yield structural unit can be quantitatively characterized by such indicators as the share of the structural units of business structure, forming their profits in the total number of structural units.

The level of funding of structural units quantified measure of the proportion of net profit of structural units in the formation of their accumulation and consumption funds.

With the development of competitive relations in the intra-level principle of economic interest has an indirect effect on the criteria for assessing changes in production of structural units.

Economic responsibility is evaluated by criteria preventative sanctions, which can be quantitatively measured by the coefficient of loss of profit structural units of the sanctions on the claims of other structural units of business structure.

The practical significance of the system of partial criteria and additional performance modifications industrial activity is that it allows you not only to assess the effectiveness of intra-economic relations in general, but also to identify the main directions of improvement of these relations.

In the current practice of industrial activity approved by the different systems and settlement targets. However, each of the existing systems must meet the requirements (Smith, 1993): to ensure consistency of core and auxiliary production, an objective assessment of the volume of production projections, its quality and efficiency, the possibility of cross-cutting plan, i.e. preserving the unity of performance planning structural units and business structure as a whole.

\subsection{Indicators of changes in planning production activities}

However, theoretical and methodological complexity of the problem, that there are many unresolved issues still requires further his studies. Work to improve the economic performance must be based on scientific principles, on the fundamental economic theory with regard to the nature and characteristics of the economic laws (Schumpeter, 1926). Before you build and improve the system performance change planning production activities, it is necessary to ascertain their nature, attributes and principles of specificity.

The composition of the targets set by each structural unit should be minimal, but sufficient for an accurate evaluation of its operations and provide a link with the main indicators of the quality results of operations of business structure.

The centerpiece of the planning activity changes the structural units should take labor productivity. The qualitative definition of the concept of productivity is that it expresses the ability to easily create specific use-values. Its quantitative certainty detected by comparing the mass of use-values with the cost of labor in their production.

Studies in production and business organizations have shown that the dynamics of labor productivity is influenced by a number of factors causing its change and thus violate the accuracy of the index over time. The most important of them are: a methodology for calculating the volume meter and change its structure as a result of the structural units of specialization and development of new products. The dynamics of labor productivity also significantly affected by improving product quality, as it is associated with additional labor costs and, therefore, this process must be reflected in 
the index of labor productivity. Seriously distorting factor is the underestimation of labor productivity of different production losses. Thus, for an objective assessment of the dynamics of labor productivity must take into account all the abovediscussed changes that influence it, in order to obtain reliable values of the index.

Do not less important indicator zatratootdachi. Using the index of costs has an impact on organizing the activities of all participants in the proceedings: how business structure as a whole and its structural units. With the help of costs reveals the degree of participation in the production units achieved "savings", and, consequently, to obtain the structure of entrepreneurial profit.

Job change costs should be set each structural unit of enterprise structure differentiated into effect on the cost of specific activities. Differentiation of tasks to change the cost of production due to a variety of factors determines the need for securing the structural units of responsibility for the validity of the calculation of production cost savings as a result of implementation activities.

The need to put into practice the specific organizational measures arises from the fact that the factors affecting the change in the cost of production, are only known artists, directly involved in planning costs, which can not affect the validity of data on changes in cost due to the factors that determine it (Shirokova, 2009).

The trend in zatratootdachi is also influenced by a number of factors distorting it. And at the rate costs affect both two groups of factors: relating to cost and volume of production. Failure to account for these factors can also lead to distorting the assessment of changes in the dynamics of the index.

A similar situation exists with indicators reflecting the effectiveness of changes in the use of fixed assets, as well as the efficiency and effectiveness of the salaries of all employees of business structure.

\section{Conclusion}

Based on the foregoing, it can be concluded that the trend towards optimal number of indicators of changes in planning production and business activities due to a number of circumstances (both objective and subjective), two of which are directly related to the problem.

Further research is advisable to carry on with regard to the following circumstances. The first is due to the fact that operating parameters change planning production and business activities are still not sufficiently reflect the contribution of each business structure and its structural units in high-quality results due to a lack of credibility is very basic, planning and reporting. This encourages replenish existing indicators and introduce a method for determining the parameters that complicate adjustment.

The second factor is related to the lack of up to date in industrial practice summarizing meter effectiveness of the changes of production activity of enterprise structure and its structural units. The effectiveness of changes of industrial activity - extremely versatile phenomenon that causes a lack of balance plans to introduce additional approved indicators for each component of the business process to the detriment of the system planned regulation of this process.

Thus, important and relevant to the science and practice is to review and methodological aspects of obtaining reliable information on all changes in production activity of enterprise structure.

This work was supported by the Ministry of Education and Science of the Russian Federation, within the public task of universities in terms of research works on the 2014-2016 years., Project number 2378.

\section{References}

Aven P. O. (1991) Economic reform. Different results from similar actions. In: Communist Economies and Economic Transformation (Abingdon), 3, pp. 417-438.

Barnett W., Carroll G. (1995) Modeling internal organizational change // Annual Review of Sociology, 21.

Bogdanov A. (1989) Tektologiya (General organizational science). In 2 books: Book 1, Moscow, Economy, 304 p.

Kleyner G. (2008) Strategy of the enterprise, Moscow, Business, 567 p.

Van de Ven A., Poole M. (1995) Explaining development and change in organizations. // Akademy of Management Review. Vol. 20. № 3.

Miller, A. (2013) Research of alternative options of integration interactions of production structures, Herald of Omsk University. Series "Economics», 3, 105-113.

Adizes I. (2011) Upravlyaya changes. - SPb: St. Petersburg, 224 p.

Williamson, O. (1979) Transaction Cost Economics: The Covernance of Contractual Relations. Journal of Economics, 22, 3-61.

Klein B. and Leffler K. (1981) The role of market forces in assuring contratual performance // Journal of Political Economy, vol. 89, August, p. $615-641$.

Huber G., Glick W. (1993) Understanding and predicting organizational change / Organizational change and redesign. New York: Oxford 
University Press.

Chambeau F., Mackenzie P. (1986) "Intrapreneurship" // Personnel j. - Costa Mesa (Cal.), Vol.65, N 7. - P.40-45.

Shermet M. (2010) Management of changes. - Moscow, The publishing house "Put", 128 p.

Chandler, A. (1990) Strategy and Structure: Chapters in the History of the American Industrial Enterprise. Cambridge: MIT Press.

Encyclopedia of changes (2010) SPb: St. Petersburg, 645 p.

Casson M. (1982) The Entrepreneur, an Economic Theory.-Martin Robertson, Oxford.

Coase R. (1937) The nature of the firm // Economica, n. s. 4,p. 386-405.

Brockhaus R.N. (1982) The Psychology of the Entrepreneur / C.A.Kent et al (eds.) Encyclopedia of Entrepreneurship. Prentice-Hall, Englewood Cliffs, New Jersey.

Smith, A. (1993) Research about the nature and the reasons of wealth of the people, Ekonov, Moscow.

Schumpeter, Josepb A. (1926) Theorie der Wirtschaftlichen Entwicklung, Ist edition. Munich and Leipzig: Duncker and Humblot.

Shirokova G. (2009) Management of changes in the Russian companies. Moscow, Publishing house "Higher school", 480 p. 